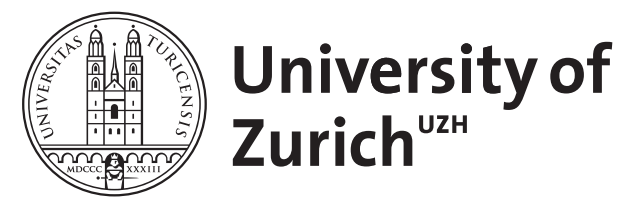

\title{
Competition and investment - A unified approach
}

\author{
Schmutzler, Armin
}

\begin{abstract}
Using a simple but general two---stage framework, this paper identifies the circumstances under which increasing competition leads to more cost---reducing investments. The framework can, for instance, capture increasing substitutability for different types of oligopoly models or changes from Cournot to Bertrand competition. The paper identifies four transmission mechanisms by which competition affects investment. For a firm with lower initial marginal costs (higher efficiency), a positive effect of competition on investment is more likely. Positive spillovers support a negative effect of competition on investment. The relation between competition and investment is not affected in an unambiguous way by the level of pre---existing competition.
\end{abstract}

DOI: https://doi.org/10.1016/j.ijindorg.2013.07.010

Posted at the Zurich Open Repository and Archive, University of Zurich

ZORA URL: https://doi.org/10.5167/uzh-84322

Journal Article

Accepted Version

Originally published at:

Schmutzler, Armin (2013). Competition and investment - A unified approach. International Journal of Industrial Organization, 31(5):477-487.

DOI: https://doi.org/10.1016/j.ijindorg.2013.07.010 


\title{
Competition and investment - A unified approach ${ }^{1,2}$
}

\author{
Armin Schmutzler ${ }^{a, 3}$ \\ ${ }^{a}$ Department of Economics, University of Zurich, and CEPR, Switzerland
}

July 2013

\begin{abstract}
Using a simple but general two-stage framework, this paper identifies the circumstances under which increasing competition leads to more cost-reducing investments. The framework can, for instance, capture increasing substitutability for different types of oligopoly models or changes from Cournot to Bertrand competition. The paper identifies four transmission mechanisms by which competition affects investment. For a firm with lower initial marginal costs (higher efficiency), a positive effect of competition on investment is more likely. Positive spillovers support a negative effect of competition on investment. The relation between competition and investment is not affected in an unambiguous way by the level of pre-existing competition.
\end{abstract}

Keywords: competition, investment, cost reduction, innovation,

\section{$\mathrm{R} \& \mathrm{D}$}

JEL: L13, L20, L22, O31

\footnotetext{
${ }^{1}$ An earlier version of this paper was circulated under the title "The relation between competition and investment - Why is it such a mess?"

${ }^{2}$ I am grateful to an anonymous referee, to Aaron Edlin, Helmut Bester, Donja Darai, Peter Funk, Dennis Gärtner, Richard Gilbert, Georg Götz, Daniel Halbheer, Andreas Hefti, Arnd Klein, Igor Letina, Tobias Markeprand, Peter Neary, Dario Sacco, Rahel Suter, Xavier Vives and seminar audiences in Aarhus, Basel, Bonn (Max-Planck-Institute), Berkeley, Cologne, Copenhagen (CIE workshop), Istanbul (EARIE), Karlsruhe (IO Panel, Verein für Socialpolitik), Tel Aviv (Recanati) and Zurich for helpful discussions. Lukas Rühli provided valuable research assistance. The paper is part of the SNF project 100012$113447 / 1$.

${ }^{3}$ Corresponding author at Department of Economics, University of Zurich, Switzerland. Tel: +41 4463 42271. E-Mail: armin.schmutzler@econ.uzh.ch
} 


\section{Introduction}

Even though economists have been trying to understand the effects of the intensity of competition on R\&D-investment for decades, the issue remains unsettled. Reasonable theoretical models can support positive, negative or non-monotone relations between competition and investment. These ambiguities reflect many modeling differences, concerning in particular the meaning of increasing competition. ${ }^{4}$ Similarly, empirical research also has been inconclusive. $^{5}$

This paper provides a uniform framework for analyzing the effects of competition on investment in a transparent way. Rather than attempting to identify an unambiguous relation between competition and investment, I ask: How does the effect of increasing competition on cost-reducing investments depend on characteristics of firms, technologies, markets and institutions, and on the specific notion of competition? The paper is not just of theoretical value. It provides a framework for empirical analysis, because it leads to various testable implications.

The model captures several notions of increasing competition and different types of oligopolies. To reveal the intuition in the most transparent fashion, I opted for simplicity otherwise by considering a two stage-duopoly. One firm (the leader) may be exogenously more efficient than the other one (the laggard), that is, it may have lower marginal costs. ${ }^{6}$ Firms simultaneously choose cost-reducing investments before they engage in product market competition, which is treated in reduced form. ${ }^{7}$ Many well-known examples are special cases. The main contributions are as follows.

The reduced form framework helps to understand the economic intuition behind these results and can be applied to many other examples. In particular, I identify four transmission channels by which competition affects investment. Specifically, I obtain the following observations concerning the

\footnotetext{
${ }^{4}$ See Gilbert (2006) and Schmutzler (2009) for recent surveys.

${ }^{5}$ See Gilbert (2006) for an elaboration of this point.

${ }^{6} \mathrm{We}$ also allow for the case that both firms are identical.

${ }^{7}$ The setting rules out situations where the investments are not observable by competitors and therefore have no strategic effect in the product market. Vives (2008) considers this case.
} 
determinants of the effects of competition on investment: (i) Increases in the initial efficiency of a firm relative to the competitor support a positive effect of competition on investment. (ii) Higher positive spillovers work towards a negative effect of competition on investment. (iii) Increases in the initial level of competition have an ambiguous effect on the relation between further competition and investment; expressed differently, U-shaped and inverse U-shaped relations between competition and innovation are possible.

Section 2 introduces the general model and defines competition in terms of its effects on equilibrium outputs and margins. It also presents examples of the general model and shows how competition affects investments in these examples. Section 3 derives properties of profits as functions of costs and the competition parameter. Section 4 discusses the comparative statics implications of these properties within the basic model. Section 5 discusses related literature very briefly. ${ }^{8}$ Section 6 concludes.

\section{The Model}

I shall consider a class of two-stage games. The assumptions are formulated as relations between equilibrium outputs and margins on the one hand and the degree of competition and the cost structure of the firms on the other. These assumptions are intuitively plausible, and they will be shown to apply in the examples below (see Section 2.2).

\subsection{Game Structure}

\subsubsection{Basics}

Initially, firm $i \in\{1,2\}$ has constant marginal cost $c_{i}^{0}$. In period 1, given $\left(c_{1}^{0}, c_{2}^{0}\right)$, firms $i=1,2$ choose investments $y_{i}$, with an increasing and convex cost function $K\left(y_{i}\right)$. In period 2, firm $i$ has marginal costs $c_{i}=c_{i}^{0}-y_{i}-\lambda y_{j}$, where $\lambda \in[0,1]$ is a spillover parameter and $j \neq i$. It will often be convenient to specify an arbitrary exogenous reference level $\bar{c} \in \mathbb{R}$ and to write $Y_{i}^{0}=$

\footnotetext{
${ }^{8}$ See Schmutzler (2009) for a more detailed treatment of related literature.
} 
$\bar{c}-c_{i}^{0}$ and $Y_{i}=\bar{c}-c_{i}$ for the firm's efficiency level before and after investment. ${ }^{9}$ Clearly, $Y_{i}=Y_{i}^{0}+y_{i}+\lambda y_{j}$.

A parameter $\theta \in \Theta \subset \mathbb{R}$ captures the intensity of competition; here $\Theta=[\underline{\theta}, \bar{\theta}]$ or $\Theta=\{\underline{\theta}, \bar{\theta}\}$ for some $\underline{\theta}<\bar{\theta}$. The defining properties of $\theta$ will be introduced in Section 2.1.2.

The demand function for firm $i$ is $q^{i}\left(p^{i}, p^{j} ; \theta\right)$; it is weakly decreasing (increasing) in $p^{i}\left(p^{j}\right)$. The product-market game is assumed to have a unique pure Nash equilibrium for each $\theta \in \Theta$ and $\left(Y_{1}, Y_{2}\right) \in \mathbf{Y} \equiv\left[\underline{Y}_{1}, \bar{Y}_{1}\right] \times\left[\underline{Y}_{2}, \bar{Y}_{2}\right]$, where $\bar{Y}_{i} \leq \bar{c}$ and $\underline{Y}_{i} \geq \bar{c}-c_{i}^{0}(i=1,2) .{ }^{10}$ The Nash equilibrium corresponds to prices $p^{i}\left(Y_{i}, Y_{j} ; \theta\right)$ for $i=1,2 ; j \neq i .^{11}$ I assume that $p^{i}\left(Y_{i}, Y_{j} ; \theta\right)$ is weakly decreasing in $Y_{i}$ and $Y_{j}, j \neq i$. The following notation will be used:

1. Equilibrium margins $M^{i}\left(Y_{i}, Y_{j} ; \theta\right) \equiv p^{i}\left(Y_{i}, Y_{j} ; \theta\right)-\bar{c}+Y_{i}$

2. Equilibrium outputs $Q^{i}\left(Y_{i}, Y_{j} ; \theta\right) \equiv q^{i}\left(p^{i}\left(Y_{i}, Y_{j} ; \theta\right), p^{j}\left(Y_{i}, Y_{j} ; \theta\right) ; \theta\right)$

3. Gross equilibrium profits $\Pi^{i}\left(Y_{i}, Y_{j} ; \theta\right)=M^{i}\left(Y_{i}, Y_{j} ; \theta\right) \cdot Q^{i}\left(Y_{i}, Y_{j} ; \theta\right)$

I will assume that $M^{i}, Q^{i}$ and thus $\Pi^{i}$ are twice continuously differentiable in $Y_{i}$ and $Y_{j}$ and, whenever $\Theta=[\underline{\theta}, \bar{\theta}]$, continuously differentiable in all variables wherever the respective function takes positive values. I use subscripts to denote partial derivatives of these functions. For instance, $M_{i}^{i} \equiv \frac{\partial M^{i}}{\partial Y_{i}}$, $M_{j}^{i} \equiv \frac{\partial M^{i}}{\partial Y_{j}}, M_{\theta}^{i} \equiv \frac{\partial M^{i}}{\partial \theta}, M_{i j}^{i} \equiv \frac{\partial^{2} M^{i}}{\partial Y_{i} \partial Y_{j}}, M_{i \theta}^{i} \equiv \frac{\partial^{2} M^{i}}{\partial Y_{i} \partial \theta}$ and $M_{j \theta}^{i} \equiv \frac{\partial^{2} M^{i}}{\partial Y_{j} \partial \theta}$. Analogous notation applies to $Q^{i}$ and $\Pi^{i}$.

The following convention will be used:

Convention: Whenever I refer to the functions $M^{i}, Q^{i}$ and $\Pi^{i}$ and their derivatives as being decreasing (increasing) in an argument, this property is required to be strict only on the set of $\left(Y_{i}, Y_{j} ; \theta\right) \in\left[\underline{Y}_{i}, \bar{Y}_{i}\right] \times\left[\underline{Y}_{j}, \bar{Y}_{j}\right] \times \Theta$ such that $\theta>\underline{\theta}$ and $Q^{i}\left(Y_{i}, Y_{j} ; \theta\right)>0$ and $Q^{j}\left(Y_{j}, Y_{i} ; \theta\right)>0$.

This convention takes care of the possibility that changes of a variable have no effect in some parameter regions because the firm is so inefficient

\footnotetext{
${ }^{9}$ The choice of $\bar{c}$ is arbitrary; to simplify calculations, I usually choose $\bar{c}=0$ or $\bar{c}=a$, where $a$ is the maximal willingness to pay for any unit of the good.

${ }^{10}$ The restrictions reflect the requirement that $0 \leq c_{i} \leq c_{i}^{0}$.

${ }^{11}$ For price competition, $p_{i}\left(Y_{i}, Y_{j} ; \theta\right)$ is the equilibrium price; for quantity competition, it denotes the market clearing price for equilibrium outputs.
} 
that outputs, margins and profits are zero. It also allows for the possibility that, when competition is very weak, the efficiency of the competitor has no effect on own outputs, margins and profits.

The following assumptions will be made throughout the paper, and they hold in examples E1-E5 below.

(A1) $Q^{i}\left(Y_{i}, Y_{j} ; \theta\right)$ is (i) increasing in $Y_{i}$, (ii) decreasing in $Y_{j}, j \neq i$.

A1(i) requires that the output increase implied by the own price reduction dominates the output reduction from the competitor price reduction; similarly for (ii). In line with the above convention, I do not require strict monotonicity everywhere for two reasons. First, when one firm has sufficiently low $Y_{i}$, its outputs may be zero and thus constant for non-degenerate sets of $Y_{i}, Y_{j} ; \theta$. Second, if $\theta=\underline{\theta}$ corresponds to the case that firms produce sufficiently unrelated products that firms do not compete, it is natural to assume that $Q^{i}$ is independent of $Y_{j}$, at least when there are no spillovers.

(A2) $M^{i}\left(Y_{i}, Y_{j} ; \theta\right)$ is (i) increasing in $Y_{i}$, (ii) decreasing in $Y_{j}, j \neq i$.

As $M^{i}\left(Y_{i}, Y_{j} ; \theta\right)=p^{i}\left(Y_{i}, Y_{j} ; \theta\right)-\bar{c}+Y_{i}$ and $M_{i}^{i}=\frac{\partial p^{i}}{\partial Y_{i}}+1$, A2(i) requires that cost reductions are larger than induced price reductions; similarly for (ii).

The investment game reduces to a one-stage game with payoff functions

$$
\pi^{i}\left(y_{i}, y_{j} ; \theta\right)=\Pi^{i}\left(Y_{i}^{0}+y_{i}+\lambda y_{j}, Y_{j}^{0}+y_{j}+\lambda y_{i} ; \theta\right)-K\left(y_{i}\right)
$$

I assume that there exists a unique interior subgame perfect equilibrium $\left(y_{1}\left(Y_{1}^{0}, Y_{2}^{0}, \theta\right), y_{2}\left(Y_{1}^{0}, Y_{2}^{0}, \theta\right)\right) .{ }^{12}$ For simplicity, I write $y_{i}(\theta) \equiv y_{i}\left(Y_{i}^{0}, Y_{j}^{0}, \theta\right)$.

\subsubsection{Defining competition}

I now introduce intuitive assumptions on the relation between $\theta$ and equilibrium outputs and margins. These assumptions hold in examples E1-E5 below and in many other examples. ${ }^{13}$

\footnotetext{
${ }^{12}$ Often, equilibria where only one firm invests coexist with the symmetric equilibria. Also, in some parameter regions all pure-strategy equilibria are asymmetric. I ignore such equilibria in the following.

${ }^{13}$ Appendix 2 gives the margins and outputs for E1-E5.
} 
(C1) $M^{i}\left(Y_{i}, Y_{j} ; \theta\right)$ is decreasing in $\theta$.

The property that competition reduces margins is standard.

(C2) $Q_{i}^{i}$ is increasing in $\theta$.

Thus the positive effect of lower costs on output is higher when competition is intense, reflecting the increasing relevance of business-stealing.

For the next property, the following definition is useful:

Definition 1 (i) Firm $i$ with efficiency level $Y_{i}^{m}$ is marginal given $\left(Y_{j} ; \theta\right)$ if $Q^{i}\left(Y_{i}, Y_{j} ; \theta\right)=M^{i}\left(Y_{i}, Y_{j} ; \theta\right)=0$ for all $Y_{i} \leq Y_{i}^{m}$ and $Q^{i}\left(Y_{i}, Y_{j} ; \theta\right)>0$ and $M^{i}\left(Y_{i}, Y_{j} ; \theta\right)>0$ for all $Y_{i}>Y_{i}^{m}$. Firm $i$ is potentially marginal given $\left(Y_{j} ; \theta\right)$ if there exists a $Y_{i}^{m} \in\left[\underline{Y}_{i}, \bar{Y}_{i}\right]$ such that firm $i$ is marginal given $\left(Y_{j} ; \theta\right)$ if it has efficiency level $Y_{i}^{m}$.

(ii) Firm $i$ is dominant given $\left(Y_{i} ; \theta\right)$ if $Y_{j} \leq Y_{j}^{m}$ for $j \neq i$. Firm $i$ is potentially dominant given $\left(Y_{j} ; \theta\right)$ if there exists $a Y_{i}^{d} \in\left[\underline{Y}_{i}, \bar{Y}_{i}\right]$ such that firm $i$ is dominant given $\left(Y_{j} ; \theta\right)$.

Thus, a marginal firm is too weak to compete, whereas a dominant firm captures the entire market. Intuitively, for a firm $i$ to be potentially marginal, the other firm has to be sufficiently strong $\left(Y_{j}\right.$ high $)$ and competition sufficiently intense; for a firm to be potentially dominant, the other firm has to be sufficiently weak ( $Y_{j}$ low) and competition has to be sufficiently intense.

(C3) For every $Y_{j} \in\left[\underline{Y}_{j}, \bar{Y}_{j}\right]$ and $\theta \in \Theta$, there exists a $Y_{i}^{*}=Y_{i}^{*}\left(Y_{j}, \theta\right) \in$ $\left[\underline{Y}_{i}, \bar{Y}_{i}\right]$ such that $Q^{i}$ is increasing in $\theta$ for $Y_{i}>Y_{i}^{*}$, and decreasing in $\theta$ for $Y_{i}<Y_{i}^{*}$. If firm $i$ is potentially marginal, then $Y_{i}^{*}=Y_{i}^{*}\left(Y_{j}, \theta\right)>\underline{Y}_{i}$. If firm $i$ is potentially dominant, then $Y_{i}^{*}=Y_{i}^{*}\left(Y_{j}, \theta\right)<\overline{Y_{i}}$.

(C3) reflects the idea that competition redistributes output from relatively inefficient to relatively efficient firms. (C3) is closely related to (C2). This is easiest to see when $Q^{i}$ is twice continuously differentiable in both variables. Then by $(\mathrm{C} 2), \frac{\partial^{2} Q^{i}}{\partial Y_{i} \partial \theta}=\frac{\partial^{2} Q^{i}}{\partial \theta \partial Y_{i}} \geq 0$, which implies that $Q_{\theta}^{i}$, the effect of competition on output, is increasing in $Y_{i}$. (C3) does not involve such a monotonicity requirement, but it implies that competition has a positive 
effect on outputs for firms that are close to being dominant and a negative effect for firms that are close to being marginal. Most of the analysis relies on $(\mathrm{C} 1)-(\mathrm{C} 3)$; the next property is only relevant for understanding the role of spillovers.

(C4) $Q_{j}^{i}$ and $M_{j}^{i}$ are decreasing in $\theta$.

Thus, lower marginal costs of the competitor reduce own outputs and margins more as competition increases.

Definition $2 \theta$ is a competition parameter if (C1)-(C4) hold.

Thus, a competition parameter has the following properties: It reduces margins; it increases output for sufficiently efficient firms and decreases output for sufficiently inefficient firms; it increases the (positive) effect of own efficiency on outputs and it increases the (negative) effect of competitor efficiency on own outputs and margins.

Clearly, other definitions of competition are conceivable. However, (C1)(C4) are sufficiently specific to rule out parameterizations which are usually not considered as increases in competition ${ }^{14}$ and general enough to be consistent with many examples. In the general model, I thus always assume that (C1)-(C4) as well as (A1) and (A2) hold.

\section{$2.2 \quad$ Examples}

\subsubsection{Assumptions}

I consider five investment games that are based on well-known oligopoly models. These examples use a specific (but common) definition of competition, namely the degree of substitution, but the insights hold more generally. The examples all satisfy (A1)-(A2) and (C1)-(C4). The section identifies aspects of the relation between competition and investment that vary across

\footnotetext{
${ }^{14}$ For instance, a symmetric increase in initial marginal costs or a reduction in the willingness to pay usually satisfies $(\mathrm{C} 1)$ and $(\mathrm{C} 2)$, but not (C3), because the effect of such parameter changes on output is negative even for leaders. In Schmutzler (2009), I do not impose any restrictions on the output effect, which limits the implications that can be obtained.
} 
examples (Observations 1 and 2), as well as properties that are robust (Observations 3 and 4). In Sections 3 and 4, I will show how Observation 1-4 can be understood as consequences of the general assumptions of the model rather than specific aspects of the examples.

For $\theta \in[0,1]$, consider the inverse demand systems

$$
\begin{array}{ll}
\text { D1: } & p^{i}\left(q_{i}, q_{j} ; \theta\right)=1-q_{i}-\theta q_{j} \\
\text { D2: } & p^{i}\left(q_{i}, q_{j} ; \theta\right)=1-\frac{1}{1+\theta} q_{i}-\frac{\theta}{1+\theta} q_{j}
\end{array}
$$

The corresponding demand functions $q^{i}\left(p^{i}, p^{j}\right)$ satisfy $\frac{\partial q^{i}}{\partial p^{j}}>0$ for $\theta>\underline{\theta}$; thus the goods are substitutes. For $\theta=0$, firms are monopolists; $\theta=1$ corresponds to homogeneous goods. Higher $\theta$ corresponds to closer substitutes. ${ }^{15}$ In addition, I consider the demand system $q^{i}\left(p^{i}, p^{j}\right)=\max \left\{\frac{p_{j}-p_{i}-\theta}{2}, 0\right\}$ (D3); this results from competition on the line à la Hotelling (where $\theta=1-t$ is the usual transportation cost parameter).

I analyze examples E1-E5, with investment cost function $K\left(y_{i}\right)=y_{i}^{2}$; where $y_{i}$ is the marginal cost reduction. Each of these examples results from a combination of price or quantity competition with one of the demand systems as follows:

\begin{tabular}{r|c|c|c} 
& Demand D1 & Demand D2 & Demand D3 \\
\hline Price Competition & Example E1 & Example E3 & Example E5 \\
Quantity Competition & Example E2 & Example E4 & \\
\hline
\end{tabular}

\subsubsection{Relation to the General Model}

The following result follows directly from the formulas for equilibrium outputs and margins given in Appendix 2.

Proposition 1 In Examples E1-E5, (A1), (A2) and (C1)-(C4) hold except possibly if $Y_{i} \gg Y_{j}{ }^{16}$

\footnotetext{
${ }^{15}$ The difference between the demand systems is that $\theta$ shifts D1 inwards, but not D2.

16 The qualification only concerns $(\mathrm{C} 1)$, which does not hold for leaders that are sufficiently close to being dominant in E2 and E4.
} 


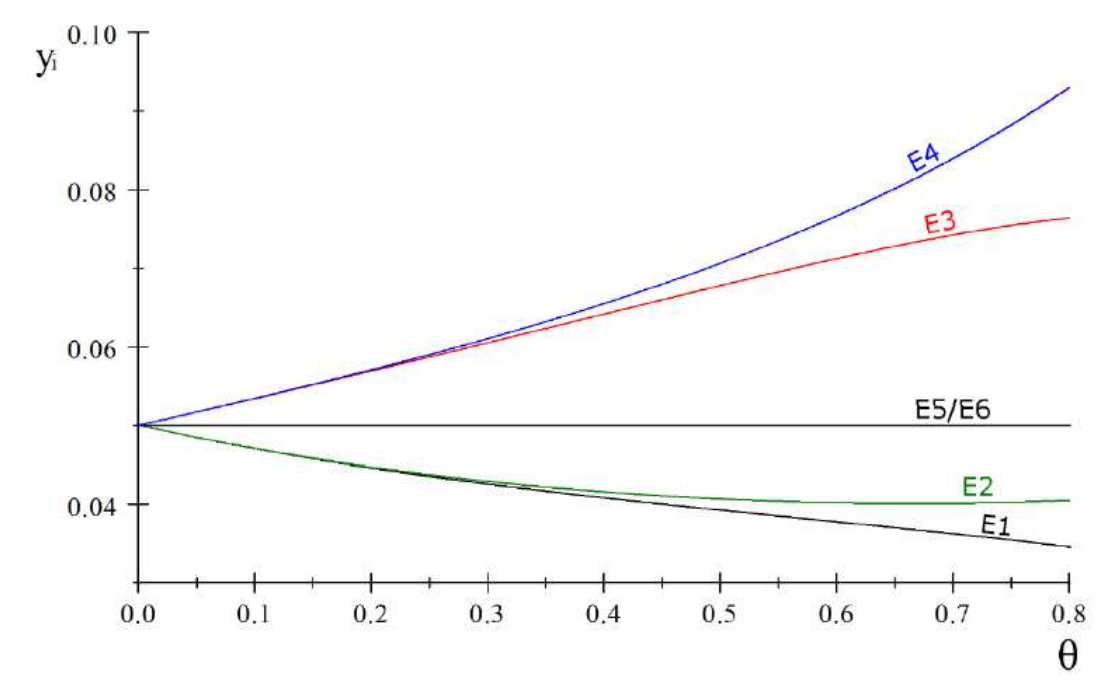

Initial marginal costs 0.85 ; for E1/E2: inverse demand function $p_{i}=1-q_{i}-\theta q_{j}$;

for E3/E4: $p_{i}=1-\frac{1}{1+\theta} q_{i}-\frac{\theta}{1+\theta} q_{j}$; equilibrium investment for E5 rescaled.

Figure 1: Equilibrium Investments with Symmetric Firms

Importantly, (C1) - (C4) are not only consistent with the interpretation of $\theta$ as substitution parameter, but also with other interpretations. For instance, (C1)-(C4) also hold if $\Theta=\{\underline{\theta}, \bar{\theta}\}$, with the interpretation that $\theta=\underline{\theta}$ corresponds to Cournot competition and $\theta=\bar{\theta}$ to Bertrand competition with parameters fixed as in any of the examples E1 to E4 (see Appendix 3). ${ }^{17}$

\subsubsection{Investments for symmetric firms}

Figure 1 plots equilibrium investments for E1-E5, assuming that $\lambda=0$ and initial marginal costs are given as 0.85 . I focus on parameter regions where a symmetric equilibrium exists in all cases. ${ }^{18}$

Figure 1 shows that investments can be increasing, decreasing, constant or U-shaped as a function $y_{i}(\theta)$.

Observation 1: The sign of the effect of competition on investment is

\footnotetext{
${ }^{17}$ The effect of changes from Cournot to Bertrand competition has been analyzed by Bester and Petrakis (1983), Delbono and Denicolò (1990) and Qiu (1997).

${ }^{18}$ In Appendix 2, I provide formulas for the equilibrium investments; the derivations are provided in the web appendix. The U-shape for E2 has been pointed out in Sacco and Schmutzler (2011).
} 
ambiguous for symmetric firms.

Moreover, the initial level of competition has no clear-cut effect on the effects of increasing competition further.

Observation 2: The equilibrium investment can be a concave or convex function of the competition parameter.

In the following, I show that the confusing picture surprisingly becomes a lot clearer when one also includes asymmetric firms.

\subsubsection{Investments for asymmetric firms}

In the above examples, suppose now that there are low-cost firms (leaders) with marginal costs 0.8 and high-cost firms (laggards) with marginal costs 0.9. Figure 2 plots equilibrium investments for E1-E5. ${ }^{19}$ The comparative statics are similar across these examples.

Observation 3: (i) For the laggard, investments are decreasing in competition. (ii) For the leader, equilibrium investments are increasing in competition, at least for $\theta$ beyond a certain threshold.

In all these examples, the statement not only holds for the specific cost values of 0.8 and 0.9 for leader and laggard, respectively, but it can be shown to hold more generally whenever the asymmetries between the two firms are sufficiently large, so that one firm is sufficiently close to being marginal. Moreover, in all examples, the effects of competition on investments are increasing in the initial efficiency of a firm, and decreasing in the initial efficiency of the competitor. ${ }^{20}$

\subsubsection{The Effects of Spillovers}

One can extend the examples by allowing for spillovers, so that firm $i$ obtains an additional cost reduction of $\lambda y_{j}(j \neq i)$, where $\lambda \in[0,1]$ measures spillovers. For E1, Figure 3 shows that $\frac{\partial y_{i}}{\partial \theta}$ is smaller with $\lambda=1$ than with

\footnotetext{
${ }^{19}$ Again, I am restricting myself to those values of $\theta$ where an equilibrium with positive investments of both firms exists for both firms even in the leader-laggard case. I also include the symmetric case with marginal costs 0.85 .

${ }^{20}$ Details are provided in the Web Appendix.
} 

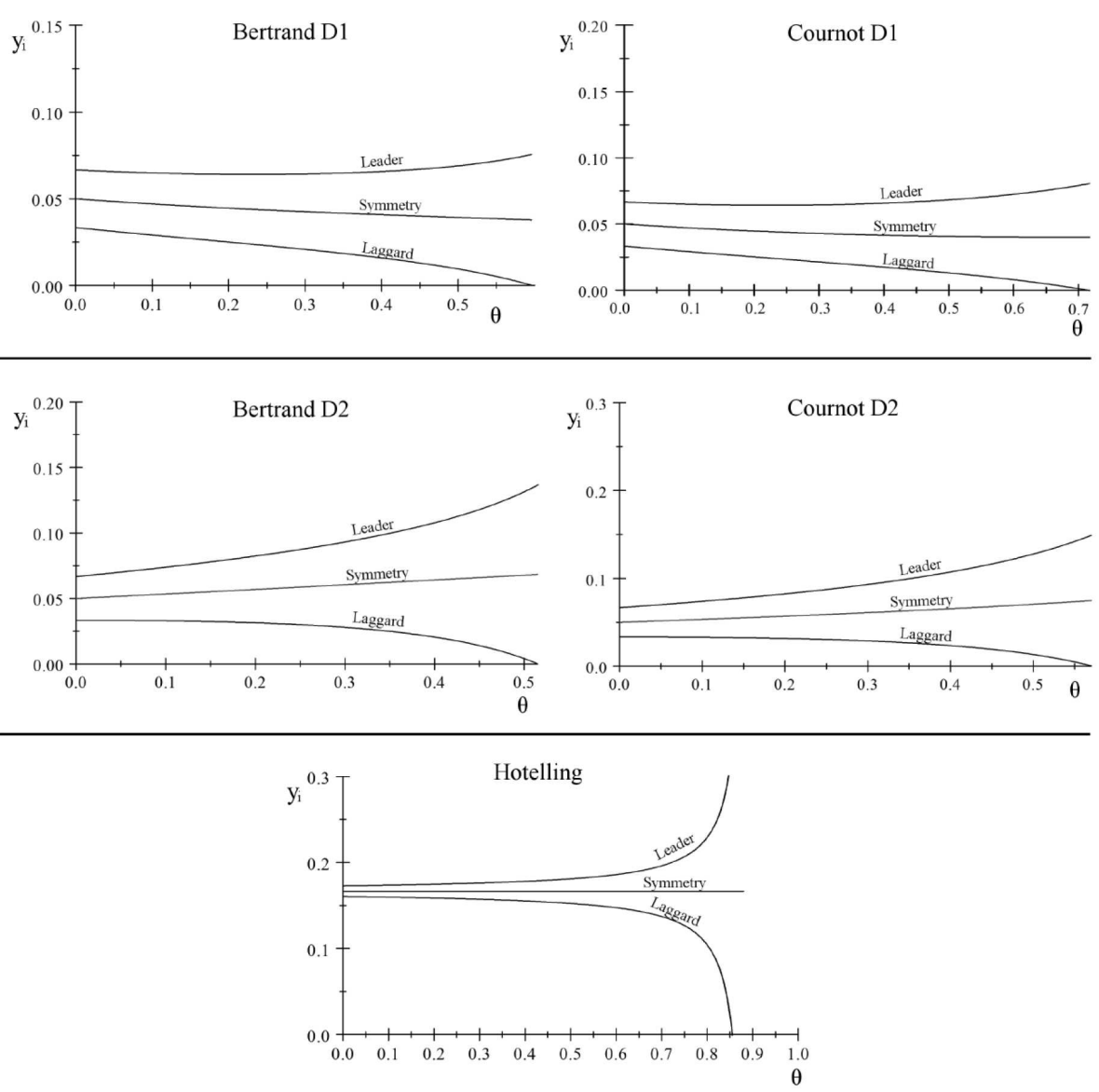

Initial marginal costs for symmetric firms: 0.85 ; for leaders: 0.8 ; for laggards: 0.9 ;

Panel 1: inverse demand $p_{i}=1-q_{i}-\theta q_{i}$ (Bertrand left, Cournot right)

Panel 2: inverse demand $p_{i}=\frac{1}{1+\theta} q_{i}-\frac{\theta}{1+\theta} q_{i}$ (Bertrand left, Cournot right)

Panel 3: Competition on the line

Figure 2: Equilibrium investments with asymmetric firms 


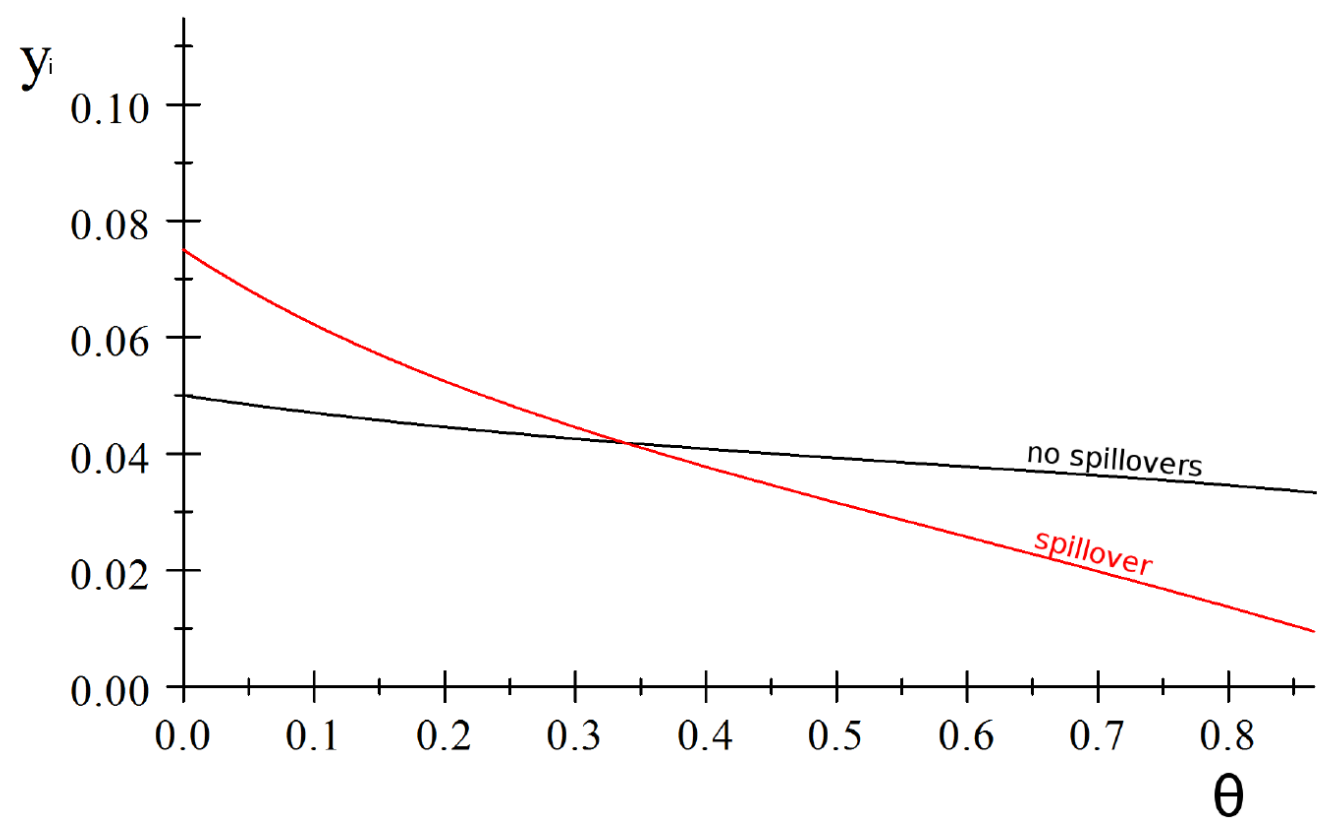

Bertrand competition; inverse demand function $p_{i}=1-q_{i}-\theta q_{j}$; initial values: $Y_{0}^{i}=$ $1-c_{0}^{i}=0.15, \lambda=1$.

Figure 3: Investments with and without spillovers (Bertrand D1)

$\lambda=1$, that is, larger in absolute value. Analogous statements can be made for examples E2-E4. ${ }^{21}$

More precisely, the following statement is shown to hold in the web appendix:

Observation 4: In E1-E4, for symmetric firms, (i) $\left.\frac{\partial y_{i}}{\partial \theta}\right|_{\lambda=1}<\left.\frac{\partial y_{i}}{\partial \theta}\right|_{\lambda=0}$ and (ii) $\frac{\partial y_{i}}{\partial \theta}$ is decreasing in $\lambda$, at least for sufficiently low initial values of $\lambda$.

Observation 4 is obviously not equivalent to the familiar statement that, because of concerns that knowledge flows to the competitor, spillovers reduce investments. As Figure 3 shows for E1, investments can be higher with spillovers than without. ${ }^{22}$ Instead, the point is that, as spillovers increase, for any initial level of competition, an increase in competition reduces invest-

\footnotetext{
${ }^{21}$ In the Hotelling Example E5, competition has no effect on equilibrium investments, no matter what $\lambda$ is.

${ }^{22}$ Intuitively, this is true because the investments of the two firms are complements: The cost reductions obtained by spillovers increase own outputs and margins and therefore increase the value of increasing margins and outputs by investing into own cost reductions.
} 
ments by a larger amount. ${ }^{23}$

\subsubsection{Summary}

The general model introduced in this section uses several intuitive assumptions. Reductions in own marginal cost and increases in competitor cost increase own outputs and margins (A1, A2). Increasing competition lowers margins $(\mathrm{C} 1)$, increases the positive output effects of lower marginal costs (C2), has positive effects on the outputs of sufficiently strong firms $\left(Y_{i}>\right.$ $\left.Y_{i}^{*}\right)$, but negative effects on the outputs of sufficiently weak firms $\left(Y_{i}<Y_{i}^{*}\right)$ (C3) and exacerbates the negative output and margin effects of increased competitor efficiency (C4).

This section also presented five introductory examples of investment games. In these examples, competition refers to the degree of substitution. For symmetric firms, increasing competition has ambiguous effects on cost-reducing investments (Observation 1); moreover the initial level of competition has ambiguous effects on the effect of further competition on investment (Observation 2). However, increasing initial efficiency of a firm has a clear positive effect on the effect of competition on investment (Observation 3) whereas increases in the strength of positive spillovers have a clear negative effect (Observation 4).

These observations are not specific to the introductory examples. Similar observations also hold in other contexts, for instance, when increasing competition is interpreted as a move from Cournot to Bertrand competition. ${ }^{24}$ It therefore seems plausible that they result from more general economic forces. To show this, I will now return to the general framework.

\section{Understanding the profit functions}

This section investigates the signs of mixed partials of the profit function $\Pi^{i}$, namely $\Pi_{i \theta}^{i}, \Pi_{i j}^{i}$ and $\Pi_{j \theta}^{i}$. The reason for doing so will become clear in Section

\footnotetext{
${ }^{23}$ In examples where the effect of competition on investments is positive, spillovers reduce the effect or even lead to a negative effect.

${ }^{24}$ See Appendix 3.
} 
4, where I provide comparative statics results in terms of these signs. First, $\Pi_{i \theta}^{i}$ is crucial: In the case without spillovers, $\Pi_{i}^{i}$, the effect of an own efficiency increase on profits, captures marginal investment incentives; $\Pi_{i \theta}^{i}$ thus determines whether $\theta$ has a positive or negative direct effect on marginal investment incentives and thus in which direction $\theta$ shifts the reaction functions in $\left(y_{1}, y_{2}\right)$-space. Second, the sign of the slope of the reaction functions (determined by the sign of $\Pi_{i j}^{i}$ ) reflects whether firms are strategic complements or substitutes. It matters for indirect effects that reflect a player's reaction to changes in the investments of the opponent. Third, to understand the role of spillovers, the mixed partial $\Pi_{j \theta}^{i}$ needs to be considered, because it states how the effect of efficiency increases of the competitor (for instance via spillovers) on own profits depends on competition.

\subsection{Competition and investment incentives}

For $\lambda=0$, marginal investment incentives can be decomposed as

$$
\Pi_{i}^{i}=M^{i} Q_{i}^{i}+Q^{i} M_{i}^{i}
$$

$M^{i} Q_{i}^{i}$ is the gain from higher output (A1), the value of which depends on the margin; $Q^{i} M_{i}^{i}$ is the gain from higher margins (A2), the value of which depends on the output level. As will be explained in Section 4.1, the comparative statics of equilibrium investments with respect to $\theta$ are closely related to the sign of $\pi_{i \theta}^{i}$. For $\lambda=0$ (no spillovers), $\pi_{i \theta}^{i}=\Pi_{i \theta}^{i}$. (4) implies

$$
\Pi_{i \theta}^{i}=Q_{i}^{i} M_{\theta}^{i}+M^{i} Q_{i \theta}^{i}+M_{i}^{i} Q_{\theta}^{i}+Q^{i} M_{i \theta}^{i}
$$

The total effect of $\theta$ on $\frac{\partial \Pi^{i}}{\partial Y_{i}}$ is thus the sum of four components, each of which has a clear interpretation and can easily be calculated for each example. ${ }^{25}$

1. By $(\mathrm{C} 1) M_{\theta}^{i} \leq 0$ and thus $Q_{i}^{i} \cdot M_{\theta}^{i} \leq 0$ : Competition reduces the

\footnotetext{
${ }^{25}$ All the statements about $M^{i}$ and $Q^{i}$ in the examples can be derived from formulas for equilibrium outputs and margins that are provided in Appendix 2. For simplicity, we shall formulate the statements in terms of mixed partials. It is straightforward to adapt the statements to the case that $\Theta$ is a discrete set, so that differentiation with respect to $\theta$ is not possible.
} 
profit margin $M^{i}$ and thus the value of increasing output by increasing efficiency. It is well-known that this effect, which I call the margin effect, works towards a reduction in investment incentives.

2. By (C2) $Q_{i \theta}^{i} \geq 0$ and thus $M^{i} \cdot Q_{i \theta}^{i} \geq 0$. Competition increases the size of the output increase resulting from higher efficiency. This output sensitivity effect reflects an increase in investment incentives.

3. For symmetric firms $Q_{\theta}^{i} \geq 0$ or $Q_{\theta}^{i} \leq 0$, depending on the example. If $Q_{\theta}^{i}>(<) 0$, there is a further reason why competition might increase (reduce) investment incentives. Competition increases (decreases) the equilibrium output and hence the value of margin increases resulting from investments. By (C3), the sign of the output effect $M_{i}^{i} \cdot Q_{\theta}^{i}$ is negative for sufficiently weak firms $\left(Y_{i}<Y_{i}^{*}\right)$ and positive for sufficiently strong firms $\left(Y_{i}>Y_{i}^{*}\right)$.

4. Because $M_{i \theta}^{i}=p_{i \theta}^{i}$, its sign reflects whether increasing competition forces firms to pass through efficiency gains to customers. I therefore refer to $Q^{i} M_{i \theta}^{i}$ as the cost-pass-through effect. In the Cournot examples E2 and E4, $M_{i \theta}^{i} \geq 0$, whereas $M_{i \theta}^{i} \leq 0$ for the Bertrand examples E1 and E3 and $M_{i \theta}^{i}=0$ for the Hotelling example E5. ${ }^{26}$ If $M_{i \theta}^{i}<0$, competition reduces the margin increase resulting from higher efficiency, which works in favor of a negative effect of competition on investments. If $M_{i \theta}^{i}>0$, the argument is reversed.

Thus, I have shown that there are four transmission channels by which competition affects marginal investment incentives. The corresponding effects of competition on investments do not all have the same sign. This fact lies behind the ambiguous relation between competition and investment.

\footnotetext{
${ }^{26}$ For Cournot competition, higher efficiency induces lower output of the competitor, which reduces $\left|p_{i}^{i}\right|$. This strategic effect is more relevant when goods are narrow substitutes. Therefore the cost-pass-through effect is positive. Under Bertrand competition, $p_{i}^{j} \leq 0$, enhancing the price-reducing effect of greater efficiency. Thus, compared to the case with little product differentiation where such considerations play no role, cost reductions induce more substantial price reductions, so that $\left|p_{i}^{i}\right|$ should increase with $\theta$. Hence, the cost-pass-through effect works towards a positive relation between competition and investment under Cournot competition, and conversely under Bertrand competition.
} 
For $\lambda>0, \pi_{i \theta}^{i}=\Pi_{i \theta}^{i}+\lambda \Pi_{j \theta}^{i}$. Thus, the sign of $\Pi_{j \theta}^{i}$ also influences the sign of $\pi_{i \theta}^{i}$. Section 3.3 will deal with this issue.

\subsection{The slope of the reaction curve}

A full analysis of the effects of competition on investment requires an understanding of how the reactions of a firm to a parameter change influence the behavior of the competitor. Thus, I explore whether investments are strategic substitutes $\left(\pi_{i j}^{i} \leq 0\right)$ or complements $\left(\pi_{i j}^{i} \geq 0\right) .{ }^{27}$ To understand the intuition, note that

$$
\Pi_{i j}^{i}=Q_{i}^{i} \cdot M_{j}^{i}+M_{i}^{i} \cdot Q_{j}^{i}+M^{i} \cdot Q_{i j}^{i}+Q^{i} \cdot M_{i j}^{i} .
$$

In linear examples like E1-E5, the last two terms disappear. $\Pi_{i j}^{i} \leq 0$ is then implied by (A2): If the competitor invests a lot, $y_{j}^{i}$ (and hence $Y_{j}^{i}$ ) is high. Therefore, $M^{i}\left(Q^{i}\right)$ is low and so are the benefits from increasing own outputs (margins) by becoming more efficient. If $\lambda=0, \pi_{i j}^{i}=\Pi_{i j}^{i}$, so that investments are strategic substitutes. If $\lambda>0, \pi_{i j}^{i}=\Pi_{i j}^{i}+\lambda\left(\Pi_{i i}^{i}+\Pi_{i j}^{i}+\Pi_{j j}^{i}\right)$. In many examples, investments become strategic complements for sufficiently large values of $\lambda$ due to the additional terms. For instance, in examples E2-E4, $\pi_{i j}^{i}>0$ for $\lambda$ sufficiently close to $1 .{ }^{28}$ This reflects the intuition that own cost reductions and cost reductions from spillovers are complementary. ${ }^{29}$

\subsection{Competition and cross profit effects}

To understand how spillovers affect marginal investment incentives, it is important to understand the sign of $\Pi_{j \theta}^{i}$ : If it is negative, increasing competition reinforces the negative effect of increasing efficiency of the opponent on a firm's profit. As discussed in Section 3.1, $\pi_{i \theta}^{i}=\Pi_{i \theta}^{i}+\lambda \Pi_{j \theta}^{i}$. Thus, if $\Pi_{j \theta}^{i}<0$, then $\pi_{i \theta}^{i}<\Pi_{i \theta}^{i}$ for $\lambda>0$, making it more difficult for a positive

\footnotetext{
${ }^{27}$ This property has been exploited in strategic trade theory (Bagwell and Staiger, 1994).

${ }^{28}$ The calculations are in the Web Appendix. In E1 and E5 investments are strategic substitutes for arbitrary levels of spillovers.

${ }^{29}$ In particular, $\Pi_{i i}^{i}>0$ can be positive, reflecting complementarities from high own output and high own markup. For related discussions, see Leahy and Neary (1997).
} 
effect of competition on marginal investment incentives to arise than in the case without spillovers. Proceeding as in (5),

$$
\Pi_{j \theta}^{i}=M^{i} \cdot Q_{j \theta}^{i}+Q^{i} \cdot M_{j \theta}^{i}+Q_{j}^{i} \cdot M_{\theta}^{i}+M_{j}^{i} \cdot Q_{\theta}^{i} .
$$

By (C4), $M^{i} \cdot Q_{j \theta}^{i} \leq 0$ and $Q^{i} \cdot M_{j \theta}^{i} \leq 0$. Moreover, $Q_{j}^{i} \cdot M_{\theta}^{i} \geq 0$ by (A1) and (C1): As competition reduces margins, it reduces the negative effect of the output reduction following a competitor's increase in efficiency. The sign of $M_{j}^{i} \cdot Q_{\theta}^{i}$ depends on whether or not $Q_{\theta}^{i} \geq 0$, that is, on whether or not $Y_{i}>Y_{i}^{*}$ (see (C3)). All told, the four components of $\Pi_{j \theta}^{i}$ have different signs, so that it is not clear whether $\Pi_{j \theta}^{i}>0$ or $\Pi_{j \theta}^{i}<0$. To obtain a more definitive result, I specify the set-up in a way that is consistent with E1 to E4, but not with E5.

(C5) For all $Y_{i} \in \mathbb{R}^{+}, Q^{i}\left(Y_{i}, Y_{j} ; \underline{\theta}\right)$ and $M^{i}\left(Y_{i}, Y_{j} ; \underline{\theta}\right)$ are independent of $Y_{j}$.

(C5) reflects the intuition that the minimal level of competition $(\underline{\theta})$ corresponds to the case where both firms are sufficiently unrelated that they act as monopolists.

Proposition 2 If (C5) holds, then there exists no $\left(Y_{i}, Y_{j}, \widetilde{\theta}\right) \in\left[\underline{Y}_{i}, \bar{Y}_{i}\right] \times$ $\left[\underline{Y}_{j}, \bar{Y}_{j}\right] \times(\underline{\theta}, \bar{\theta}]$ such that $\Pi_{j \theta}^{i}\left(Y_{i}, Y_{j} ; \underline{\theta}\right)>0$ holds everywhere on $(\underline{\theta}, \tilde{\theta})$.

Intuitively, for monopolists cost reductions of the other firm have no effect on own profits as long as own costs remain the same, whereas the effects become negative as competition increases. Thus, starting from a monopoly, competition cannot have a positive effect on $\Pi_{j}^{i}$. In spite of the abovementioned ambiguities, the results are stronger in examples E1-E4 where, for symmetric firms, $\Pi_{j \theta}^{i} \leq 0$ holds globally, rather than just for low levels of competition. ${ }^{30}$

\section{Equilibrium investments}

In Section 3.1, I showed under which circumstances increases in competition shift out the reaction curve, that is, $\pi_{i \theta}^{i} \geq 0$. In Section 4.1, I will add

\footnotetext{
${ }^{30}$ Calculations are provided in the Web Appendix.
} 
conditions that, together with $\pi_{i \theta}^{i} \geq 0$, guarantee that competition has a weakly positive effect on equilibrium investments. Section 4.2 characterizes parameter changes that favor such an effect.

\subsection{Comparative statics}

I now assume that $\Theta=[\underline{\theta}, \bar{\theta}]$, and $\pi^{i}\left(y_{i}, y_{j} ; \theta\right)$ is concave and twice continuously differentiable. When $\pi_{i \theta}^{i}>0, \theta$ shifts out player $i$ 's reaction curve. Total differentiation of the first-order conditions gives

$$
\left(\begin{array}{cc}
\pi_{i i}^{i} & \pi_{i j}^{i} \\
\pi_{j i}^{j} & \pi_{j j}^{j}
\end{array}\right)\left(\begin{array}{c}
d y_{i} \\
d y_{j}
\end{array}\right)=\left(\begin{array}{c}
-\pi_{i \theta}^{i} d \theta \\
-\pi_{j \theta}^{j} d \theta
\end{array}\right)
$$

Solving for $\frac{d y_{i}}{d \theta}$ yields

$$
\frac{d y_{i}}{d \theta}=-\frac{\pi_{i \theta}^{i} \pi_{j j}^{j}-\pi_{i j}^{i} \pi_{j \theta}^{j}}{\pi_{i i}^{i} \pi_{j j}^{j}-\pi_{i j}^{i} \pi_{j i}^{j}}
$$

This term contains the direct effect of $\theta$ (shift of the reaction curve) and a multiplier capturing indirect effects (reactions to competitor adjustments). For symmetric firms, (6) can be rewritten as

$$
\frac{d y_{i}}{d \theta}=-\frac{\pi_{i \theta}^{i}}{\pi_{i i}^{i}+\pi_{i j}^{i}}=-\frac{\pi_{i \theta}^{i}}{\pi_{i i}^{i}} \frac{\pi_{i i}^{i}}{\pi_{i i}^{i}+\pi_{i j}^{i}} .
$$

The term $-\frac{\pi_{i \theta}^{i}}{\pi_{i i}^{i}}$ is the direct effect; $\frac{\pi_{i i}^{i}}{\pi_{i i}^{i}+\pi_{i j}^{i}}$ is the multiplier. The following proposition, which immediately follows from (6), specifies a necessary and sufficient condition for a weakly positive effect of competition on investment. $^{31}$

Proposition 3 If, for $i=1,2$ and $j \neq i$, the Hahn stability condition

\footnotetext{
${ }^{31}$ It is well known that similar results hold for oligopoly models (e.g. Shapiro 1989). By switching the signs in (8), one obtains sufficient conditions for negative effects of competition on investment.
} 
$\left(\pi_{i i}^{i} \pi_{j j}^{j}>\pi_{i j}^{i} \pi_{j i}^{j}\right)$ holds, then $y_{i}(\theta)$ is weakly increasing in $\theta$ if and only if

$$
\pi_{i \theta}^{i} \geq \frac{\pi_{i j}^{i}}{\pi_{j j}^{j}} \pi_{j \theta}^{j} .
$$

Proposition 3 has the following immediate implications:

Corollary 1 If, for $i=1,2$ and $j \neq i$, the Hahn stability condition holds, then $y_{i}(\theta)$ is weakly increasing in $\theta$ if (i) or (ii) holds:

(i) $\pi_{i \theta}^{i} \geq 0$ and $\pi_{i j}^{i} \equiv \frac{\partial^{2} \pi^{i}}{\partial y_{i} \partial y_{j}} \geq 0$.

(ii) $\pi_{i \theta}^{i} \geq 0, \pi^{i}\left(y_{i}, y_{j} ; \theta\right)$ is symmetric; $y_{i}(\theta)=y_{j}(\theta)$ for all $\theta$ considered.

To understand (i), consider Figure 4. $\theta=L(H)$ refers to the situation

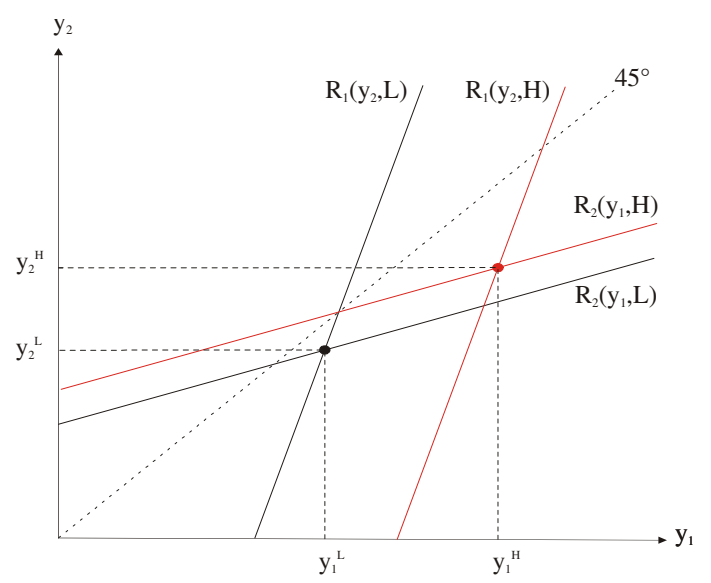

Figure 4: Strategic Complements

before (after) a parameter increase. Because $\pi_{i \theta}^{i} \geq 0$, reaction functions shift out as $\theta$ increases. The supermodularity condition in (i), $\pi_{i j}^{i}=\Pi_{i j}^{i} \geq 0$, implies increasing reaction functions, so that the indirect effects of competition reinforce the direct effects. Thus, competition increases both players' investments.

However, as argued in Section 3.2, unless spillovers are large, investments are strategic substitutes in many examples (e.g., E1-E5), so that the direct and indirect effects have opposite signs. Even then, for symmetric $\pi^{i}$, part (ii) of Proposition 3 shows that, if $\pi_{i \theta}^{i} \geq 0$ for $i=1,2$, competition increases both firms' investments (see Figure 5). However, with asymmetric 


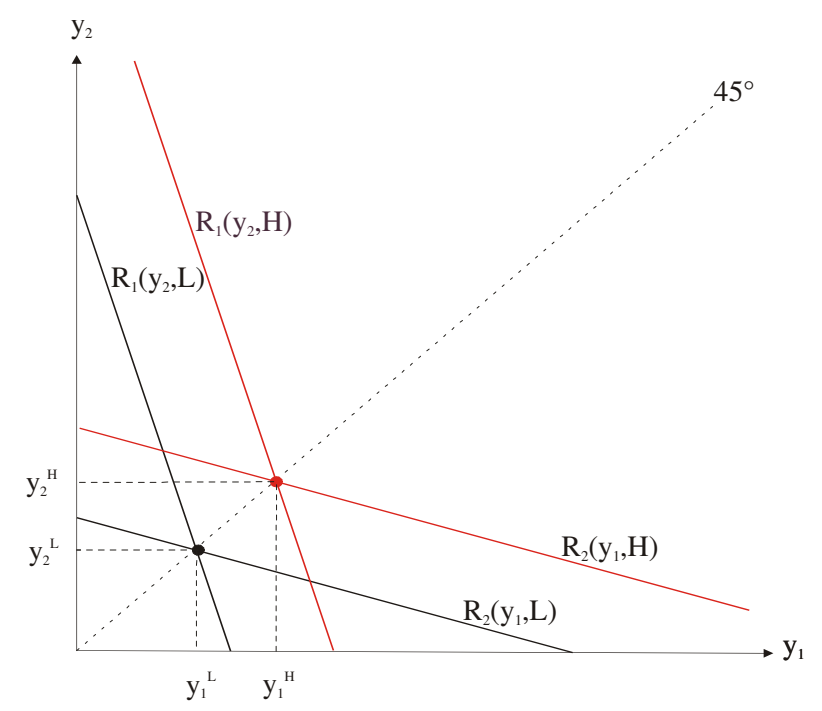

Figure 5: Strategic Substitutes (Symmetric Case)

firms and strategic substitutes it is simple to construct examples such that only one firm increases its investments, even though both reaction functions shift outwards as competition increases. ${ }^{32}$ Even so, an outward shift of both reaction functions guarantees a weakly positive effect on both equilibrium investments as long as reactions to changes in the other player's investment are not too strong. This requirement is captured by the more general condition (8), which implies both (i) and (ii).

The next result follows from (6). It identifies situations where competition weakly increases the investments of one firm and decreases those of the other one.

Proposition 4 Suppose for some $i \in\{1,2\}$ and $j \neq i$, the following conditions hold: (a) $\pi_{i \theta}^{i} \geq 0$; (b) $\pi_{j \theta}^{j} \leq 0$; (c) $\pi_{i j}^{i} \leq 0$ and (d) $\pi_{j i}^{j} \leq 0$. Then $y_{i}$ is weakly increasing in $\theta$ and $y_{j}$ is weakly decreasing in $\theta$.

By (a) and (b), $\theta$ shifts out firm $i$ 's reaction curve and shifts firm $j$ 's reaction curve inwards (Figure 6). By (c) and (d), these direct effects are

\footnotetext{
${ }^{32}$ Intuitively, if the shift is more pronounced for firm 1 than for firm 2, and the reaction function of firm 2 is sufficiently steep, then the direct positive effect of competition on investment for firm 2 is outweighed by the negative effect that firm 1 increases investments, to which firm 2 reacts by reducing investments.
} 


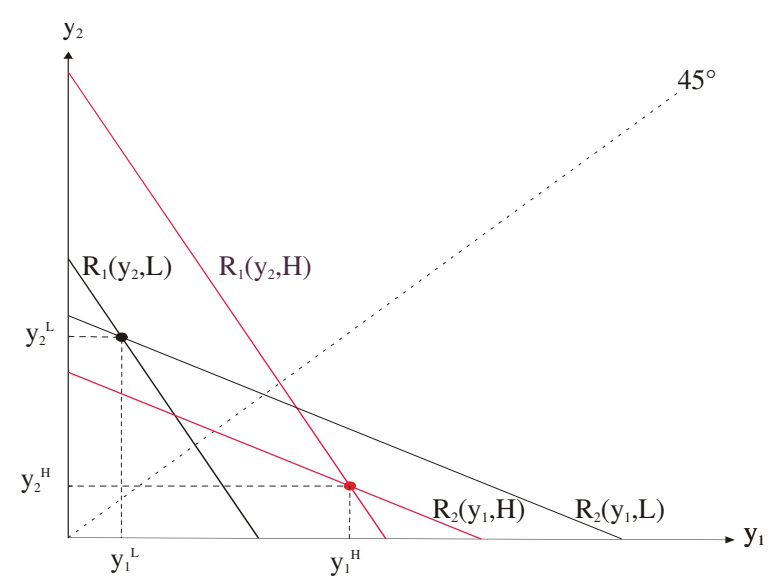

Figure 6: Asymmetric Effects on Investment Incentives

mutually reinforcing: As both reaction functions are decreasing, an increase of firm $i$ 's investment reduces firm $j$ 's investment incentives and vice versa.

A nice application of Proposition 4 is the Hotelling example (E5). There, the sign of $\Pi_{i \theta}^{i}$ and hence of $\pi_{i \theta}^{i}$ is determined by whether firm $i$ is leader or laggard, that is, whether $c_{i}^{0}<c_{j}^{0}$ or $c_{i}^{0}>c_{j}^{0}$. (see Appendix 2). Also, $\Pi_{i j}^{i}<0$. Therefore the proposition shows why the sign of $\frac{\partial y_{i}}{\partial \theta}$ differs for leaders and laggards.

To sum up, this subsection has provided conditions under which the sign of the direct effect of competition on the reaction curve (the sign of $\Pi_{i \theta}^{i}$ ) determines the sign of the effect of competition on equilibrium investments. Specifically, Proposition 3 identified circumstances under which competition increases both firms' investments, whereas Proposition 4 identified conditions under which one firm's investment increases, whereas the other firm's investment decreases.

\subsection{Determinants of the Effects of Competition}

In Section 3, I have shown why $\Pi_{i \theta}^{i}$ can be positive or negative. This explains Observation 1 that there is no general relation between competition and equilibrium investments. Encouraged by Observations 3 and 4, I instead identify circumstances that lead to a positive or negative relation between competition and investment, respectively. I will first deal with general parameters, 
then with specific cases.

\subsubsection{General results}

The first result is useful to determine which factors work towards a positive effect of competition and investment for symmetric firms. ${ }^{33}$ To this end, I consider the effect of increasing an arbitrary parameter $\alpha$ that enters the profit function, and I ask under which circumstances the parameter increase has a positive effect on the effect of competition on investment.

Proposition 5 Suppose $\pi^{i}=\pi^{i}\left(y_{i}, y_{j} ; \theta ; \alpha\right)$ for some parameter $\alpha \in \Re$, with $\pi_{i \theta}^{i} \geq 0$. Suppose $\pi^{i}$ is symmetric and differentiable and a symmetric equilibrium $y^{i}(\theta, \alpha)$ exists. Finally suppose the Hahn stability condition holds. Then $\frac{\partial}{\partial \alpha}\left(\frac{\partial y^{i}}{\partial \theta}\right) \geq 0$ if and only if

$$
\frac{\partial}{\partial \alpha} \ln \pi_{i \theta}^{i} \geq \frac{\partial}{\partial \alpha} \ln \left(-\left(\pi_{i i}^{i}+\pi_{i j}^{i}\right)\right)
$$

Thus, starting with a situation where competition increases marginal investment incentives $\left(\pi_{i \theta}^{i} \geq 0\right)$, an increase of $\alpha$ strengthens the positive effect of competition on equilibrium investments if and only if (9) holds.

The result can be understood using (7). A change of $\alpha$ potentially affects the direct effect of competition $-\frac{\pi_{i \theta}^{i}}{\pi_{i i}^{i}}$ and the multiplier $\frac{\pi_{i i}^{i}}{\pi_{i i}^{i}+\pi_{i j}^{i}}$. A high value of $\frac{\partial}{\partial \alpha} \ln \pi_{i \theta}^{i}$ favors a positive effect of $\alpha$ on the direct effect. ${ }^{34}$ However, if $\alpha$ has sufficiently strong effects on $\pi_{i i}^{i}$ and $\pi_{i j}^{i}$ and thus on the multiplier, the signs of $\frac{\partial}{\partial \alpha}\left(\frac{\partial y_{i}}{\partial \theta}\right)$ and $\pi_{i \theta \alpha}^{i}$ need not coincide.

\subsubsection{Initial Efficiency}

Observation 3 identifies the effect of initial efficiency on $\frac{\partial y_{i}}{\partial \theta}$. It states that, in the specific examples E1-E5, the effect of competition on investments is positive for the leader and negative for the laggard. The latter statement

\footnotetext{
${ }^{33} \mathrm{An}$ analogous condition for the asymmetric case is simple to derive, but not very transparent.

${ }^{34}$ Note that $\frac{\partial}{\partial \alpha}\left(-\frac{\pi_{i \theta}^{i}}{\pi_{i i}^{i}}\right)>0$ if and only if $\frac{\pi_{i \theta \alpha}^{i}}{\pi_{i \theta}^{i}}>\frac{\pi_{i i \alpha}^{i}}{\pi_{i i}^{i}}$.
} 
generalizes in the sense that, for firms with efficiency levels below a certain threshold, the effect of competition on investment incentives is always negative.

Proposition 6 Suppose that firm $i$ is potentially marginal. Then there exists an $\varepsilon>0$ such that $\Pi_{i \theta}^{i}\left(Y_{i}, Y_{j} ; \theta\right)<0$ on the interval $\left(Y_{i}^{m}, Y_{i}^{m}+\varepsilon\right)$, where $Y_{i}^{m}$ is the efficiency level of the marginal firm.

Recall that a firm is potentially marginal if competition is sufficiently intense and the competitor sufficiently strong that the firm produces zero output if it is sufficiently inefficient. Intuitively, Proposition 6 states that, for firms that are sufficiently weak that they barely survive, the cost-pass through effect and the positive output-sensitivity effect (C2) have very little value because outputs and margins are close to zero, whereas by $(\mathrm{C} 1)$ and (C3) the margin and output effects are negative. ${ }^{35}$

It is also intuitive why $\Pi_{i \theta}^{i}$ tends to be increasing in the initial efficiency level $Y_{0}^{i}$. By $(\mathrm{C} 2), Q_{\theta}^{i}$ is increasing in $Y_{i}$. Hence, the output effect $\left(M_{i}^{i} \cdot Q_{\theta}^{i}\right)$ is increasing in $Y_{i}$ for any fixed level of $M_{i}^{i}$. This works towards a positive effect of $Y_{0}^{i}$ on the effect of competition on investment. Also, because margins are higher for more efficient firms by (A2), the positive output-sensitivity effect $M^{i} \cdot Q_{i \theta}^{i}$ tends to be larger for more efficient firms. Together, these arguments help to explain why $\frac{\partial y_{i}}{\partial \theta}$ is higher for more efficient firms.

\subsubsection{Spillovers}

By Observation 4, higher spillovers reduce $\frac{\partial y_{i}}{\partial \theta}$. The following result identifies the general forces behind this result.

Proposition 7 Suppose that (i) $\frac{\partial^{3} \Pi^{i}}{\partial Y_{i} \partial Y_{j} \partial \theta}=\frac{\partial^{3} \Pi^{i}}{\left(\partial Y_{i}\right)^{2} \partial \theta}=\frac{\partial^{3} \Pi^{i}}{\left(\partial Y_{j}\right)^{2} \partial \theta}=0$ for $i=$ $1,2, j \neq i$ or $(i i) K^{\prime}(0)$ is sufficiently large. As spillovers $(\lambda)$ increase, $\pi_{i \theta}^{i}$ falls.

In this proposition, (C4) plays a crucial role. As competition increases, firms become more concerned about positive effects of spillovers of their in-

${ }^{35}$ (C4) is not needed for Proposition 6. 
vestment. The other conditions are more subtle, they control effects of unclear signs that might interfere with this more fundamental effect. ${ }^{36}$ Continuity arguments imply that (i) still holds as long as the corresponding third derivatives are sufficiently small.

\subsubsection{Pre-existing competition}

It seems intuitive that, while some competition is good for investments, "excessive competition" may have negative effects, suggesting an inverse-U relation between competition and investment. Indeed, Aghion et al. (1997, 2001) derive such a relation between competition and investment from industry composition effects (see Section 5).

Example E2 shows that nevertheless a U-shape may arise. (5) helps to improve the intuition. Set $\alpha=\theta$. An increase in $\alpha=\theta$ reduces the negative effect of $\theta$ on margins, that is, $M_{\theta \theta}^{i}>0$, so that the absolute value of the negative margin effect $\left(Q_{i}^{i} M_{\theta}^{i}\right)$ becomes smaller. ${ }^{37}$ When competition has already reduced margins substantially, further competition does not reduce them much more, that is, the negative margin effect essentially disappears. This favors a positive effect of competition at high initial levels of competition. Even so, (5) together with $(\mathrm{C} 2)$ gives two reasons why $y^{i}(\theta)$ is sometimes concave. First, with low competition, margins and hence the output sensitivity effect $\left(M_{i} Q_{i \theta}^{i}\right)$ are high. Second, by $(\mathrm{C} 2), Q_{i}^{i}$ is higher when competition is intense, suggesting that the negative margin effect $Q_{i}^{i} M_{\theta}^{i}$ is more pronounced when competition is intense. Hence, there are forces in favor of a positive effect of $\theta$ on $\frac{\partial y_{i}}{\partial \theta}$ and forces favoring a negative effect. Which of them dominate is unclear a priori.

\subsubsection{Summary}

This section shows that a high initial efficiency and low spillovers work quite generally in favor of a positive effect of competition and investment, whereas

\footnotetext{
${ }^{36}$ As spillovers increase, the overall cost level becomes lower for any given investment vector; this potentially affects the relation between competition and marginal investment incentives. The proof gives a condition that is weaker than both (i) and (ii) and makes sure such effects do not dominate.

${ }^{37}$ This property also holds in examples E1 and E3-E5.
} 
the level of pre-existing competition has no clear effect. Thus, the insights from the specific examples E1-E5 carry over to any model satisfying the assumptions of the basic model.

\section{$5 \quad$ Related Literature}

The literature on competition and investment is so large that I only address the most closely related contributions. ${ }^{38}$

The most comprehensive treatment of two-stage models of investment is Vives (2008). ${ }^{39}$ He presents several examples in a unified framework. Apart from the fact that Vives does not introduce the four transmission channels, the most conspicuous difference in his treatment of two-stage games without entry is that he only considers symmetric firms. The differential effects of competition on leaders and laggards, which are central to my paper, are therefore not an issue.

Boone (2000) deals with asymmetric firms. He also uses an abstract approach to define competition. However, this approach is very different from mine. He defines competition in terms of its effect on investment incentives and on gross profits. ${ }^{40}$ I define competition in more basic terms (focusing on the effects of margins and outputs) and show how the effects on investments can be understood as a consequence of these more basic properties.

Asymmetry between firms is also crucial for recent growth models. For instance, Aghion et al. (1997, 2001) use oligopoly models with potentially asymmetric firms as building blocks. ${ }^{41}$ These models are similar to the ones I discussed; however, investments are discrete. Increasing competition (moving from Cournot to Bertrand or increasing the degree of substitution) has the

\footnotetext{
${ }^{38}$ In Schmutzler (2009), I provide a detailed survey, focusing on the theoretical literature. There I also sketch some of the ideas from the previous version of the current paper in an informal way. I use the decomposition (5) to organize the examples; I briefly report on the role of the initial efficiency and on some of the extensions of the basic model.

${ }^{39}$ For elementary models on this topic, see Motta (2004, ch.2).

${ }^{40} \mathrm{An}$ increase in competition takes profits and marginal investment incentives through up to four regimes which differ with respect to the effect of competition on profits and investment incentives.

${ }^{41}$ Denicolo and Zanchettin (2009) consider similar quality ladder models where multiple firms compete as Bertrand or Cournot competitors.
} 
effect that there is a lot of investment when firms are equally efficient initially, but less investment when firms are asymmetric. This yields an industrycomposition effect that, even though competition makes firms want to invest a lot when they are symmetric, this very fact often brings them into states where they are asymmetric and hence invest less.

In the working paper, I show that, if one goes beyond the framework introduced in Section 2, one can identify other determinants of the relation between competition and investment. For instance, building from Schmidt (1996), I show that separation of ownership and control fosters a positive relation between competition and cost reductions. ${ }^{42}$ Related to arguments of Raith (2003) and Vives (2008), I also argue that low entry costs work towards such a positive relation. ${ }^{43}$

Several papers consider investments when an incumbent is threatened by potential entry. Weinschenk (2010) analyzes how the investments of an incumbent are affected by the size of the potential entry threat. Segal and Whinston (2007) show how antitrust polices that restrict the behavior of incumbents towards the entrant can have ambiguous investment incentives. ${ }^{44}$

Finally, there is a vast empirical literature that has often been surveyed. ${ }^{45}$ Most of the papers deal with the relation between innovation and measures of firm size or market concentration that correspond loosely to concepts of increasing competition as they are used in the theoretical literature. The current paper can be used to guide empirical research: By identifying conditions which foster a positive effect between competition and cost-reducing investments, it provides predictions for the signs of the coefficients of interaction terms between competition and other parameters in regressions that explain process innovations.

\footnotetext{
${ }^{42}$ Hart (1983), Hermalin (1992) and Raith (2003) also consider the effects of competition on managerial efforts.

${ }^{43}$ Also broadly related is the patent race literature (e.g. Loury, 1979; Lee and Wilde, 1980) which analyzes the effects of the number of firms competing for a patent on the innovation effort.

${ }^{44}$ In terms of $(\mathrm{C} 1)-(\mathrm{C} 3)$, these policies can be regarded as reductions in competition, even though the authors consider them as pro-competitive.

${ }^{45}$ Among the many surveys on the subject, Gilbert (2006) is an example that contains many insightful comments on this literature and the relation to the theoretical models.
} 


\section{Conclusion}

Many examples show that, while competition has ambiguous effects on the investments of symmetric firms, the effects are negative for laggards and are more likely to become positive for firms that are initially relatively efficient. Spillovers work towards a negative effect of competition on investment. The role of the initial level of competition for the effect of further increases in competition is ambiguous. The paper introduces a general framework to make the sources of these effects transparent. Specifically, it identifies four transmission channels by which competition affects investments, and it shows how the observations are related to more basic properties of competition.

Among several further conceivable extensions, it would be interesting to extend the approach to product innovations. A decomposition of investment incentives analogous to (5) would help to understand how the effects of competition on product innovation differ from those on process innovation. ${ }^{46}$

\section{Appendix}

\subsection{Appendix 1: Proofs}

\subsubsection{Proof of Proposition 2}

By (C4), $Q^{i}$ and $M^{i}$ and hence $\Pi^{i}$ are strictly decreasing in $Y_{j}$ for any $\theta>\underline{\theta}$ such that $Q^{i}>0$ and $M^{i}>0$. By (C5), $\Pi_{j}^{i} \geq 0$ for $\theta=\underline{\theta}$. Thus, $\Pi_{j \theta}^{i}>0$ cannot hold everywhere in a neighborhood of $\underline{\theta}$.

\subsubsection{Proof of Proposition 3}

(7) implies

$$
\frac{\partial}{\partial \alpha}\left(\frac{\partial y^{i}}{\partial \theta}\right)=\frac{-\pi_{i \theta \alpha}^{i}\left(\pi_{i i}^{i}+\pi_{i j}^{i}\right)+\pi_{i \theta}^{i}\left(\pi_{i i \alpha}^{i}+\pi_{i j \alpha}^{i}\right)}{\left(\pi_{i i}^{i}+\pi_{i j}^{i}\right)^{2}}
$$

\footnotetext{
${ }^{46}$ Product innovation is less straightforward to model than process innovation. For instance, an innovating firm may want to continue to use the old product (Greenstein and Ramey 1998, Chen and Schwartz 2013). Gilbert (2006) summarizes some arguments pertaining to this discussion, see also Schmutzler (2009).
} 
Thus $\frac{\partial}{\partial \alpha}\left(\frac{\partial y^{i}}{\partial \theta}\right) \geq 0$ if and only if $\pi_{i \theta}^{i}\left(\pi_{i i \alpha}^{i}+\pi_{i j \alpha}^{i}\right) \geq \pi_{i \theta \alpha}^{i}\left(\pi_{i i}^{i}+\pi_{i j}^{i}\right)$. By the Hahn condition and symmetry $\pi_{i i}^{i}+\pi_{i j}^{i}<0$. Applying $\frac{\partial f / \partial \alpha}{f(\alpha)}=\frac{\partial}{\partial \alpha}(\ln (f(\alpha))$ to the positive-valued functions $\pi_{i \theta}^{i}(\alpha)$ and $-\left(\pi_{i i}^{i}(\alpha)+\pi_{i j}^{i}(\alpha)\right)$, one obtains (9).

\subsubsection{Proof of Proposition 6}

By (A1) and (C1), $Q_{i}^{i} \cdot M_{\theta}^{i}<0$ whenever both firms have positive outputs; by (A2) and (C3) $M_{i}^{i} \cdot Q_{\theta}^{i}<0$ for $Y_{i}<Y_{i}^{*}$. Moreover $M^{i} Q_{i \theta}^{i}+Q^{i} M_{i \theta}^{i}=0$ for $Y_{i}=Y_{i}^{m}$. Thus, by continuity there exists an $\varepsilon>0$ such that $\Pi_{i \theta}^{i}=$ $Q_{i}^{i} M_{\theta}^{i}+M_{i}^{i} Q_{\theta}^{i}+M^{i} Q_{i \theta}^{i}+Q^{i} M_{i \theta}^{i}<0$ for $Y_{i} \in\left(Y_{i}^{m}, Y_{i}^{m}+\varepsilon\right)$.

\subsubsection{Proof of Proposition 7}

$$
\begin{aligned}
\frac{\partial^{2} \pi^{i}\left(y_{i}, y_{j} ; \theta\right)}{\partial y_{i} \partial \theta}= & \frac{\partial^{2} \Pi^{i}\left(Y_{i}^{0}+y_{i}+\lambda y_{j}, Y_{j}^{0}+y_{j}+\lambda y_{i} ; \theta\right)}{\partial Y_{i} \partial \theta} \\
& +\lambda \frac{\partial^{2} \Pi^{i}\left(Y_{i}^{0}+y_{i}+\lambda y_{j}, Y_{j}^{0}+y_{j}+\lambda y_{i} ; \theta\right)}{\partial Y_{j} \partial \theta}
\end{aligned}
$$

Therefore,

$$
\begin{gathered}
\frac{\partial^{3} \pi^{i}\left(y_{i}, y_{j} ; \theta\right)}{\partial y_{i} \partial \theta \partial \lambda}= \\
\frac{\partial^{2} \Pi^{i}}{\partial Y_{j} \partial \theta}+y_{j}\left(\frac{\partial^{3} \Pi^{i}}{\left(\partial Y_{i}\right)^{2} \partial \theta}+\frac{\partial^{3} \Pi^{i}}{\partial Y_{i} \partial Y_{j} \partial \theta}\right)+y_{i}\left(\frac{\partial^{3} \Pi^{i}}{\partial Y_{i} \partial Y_{j} \partial \theta}+\frac{\partial^{3} \Pi^{i}}{\left(\partial Y_{j}\right)^{2} \partial \theta}\right)
\end{gathered}
$$

If (i) holds, $\frac{\partial^{3} \pi^{i}\left(y_{i}, y_{j} ; \theta\right)}{\partial y_{i} \partial \partial \partial \lambda}=\frac{\partial^{2} \Pi^{i}}{\partial Y_{j} \partial \theta}<0$. Next, consider (ii). If $y_{i}=y_{j}=0$, then $\frac{\partial^{2} \Pi^{i}}{\partial Y_{j} \partial \theta}<0$. $K^{\prime}\left(y_{i}\right)$ is bounded below by $K^{\prime}(0)$ by convexity. Therefore, for any given functional form of $\Pi^{i}$, as $K^{\prime}(0)$ increases, the best response $y_{i}$ converges to zero. Hence, by continuity of $\frac{\partial^{2} \Pi^{i}}{\partial Y_{j} \partial \theta}, \frac{\partial^{3} \pi^{i}\left(y_{i}, y_{j} ; \theta\right)}{\partial y_{i} \partial \theta \partial \lambda}<0$. 


\subsection{Appendix 2: The Examples}

I provide the equilibrium outputs, margins and investments for E1-E5. ${ }^{47}$ Assume that $Y_{i}=1-c_{i}$ in E1-E4, that is, $\bar{c}=1$. With the formulas below in place, the claims in the main text become straightforward to derive. ${ }^{48}$

With Bertrand competition and inverse demand D1,

$$
\begin{aligned}
& Q^{i}\left(Y_{i}, Y_{j} ; \theta\right)=\frac{\left(2-\theta^{2}\right) Y_{i}-\theta Y_{j}}{\left(4-\theta^{2}\right)\left(1-\theta^{2}\right)} ; M^{i}\left(Y_{i}, Y_{j} ; \theta\right)=\frac{\left(2-\theta^{2}\right) Y_{i}-\theta Y_{j}}{4-\theta^{2}} \\
& y_{i}(\theta)=-\frac{-12 Y_{i}^{0}+8 \theta Y_{j}^{0}+16 \theta^{2} Y_{i}^{0}-6 \theta^{3} Y_{j}^{0}-7 \theta^{4} Y_{i}+\theta^{5} Y_{j}^{0}+\theta^{6} Y_{i}^{0}}{-76 \theta^{2}+45 \theta^{4}-11 \theta^{6}+\theta^{8}+36}
\end{aligned}
$$

With Cournot competition and inverse demand D1,

$$
\begin{aligned}
& Q^{i}\left(Y_{i}, Y_{j} ; \theta\right)=M^{i}\left(Y_{i}, Y_{j} ; \theta\right)=\frac{2 Y_{i}-\theta Y_{j}}{4-\theta^{2}} . \\
& y_{i}(\theta)=-\frac{12 Y_{i}^{0}-8 \theta Y_{j}^{0}-4 \theta^{2} Y_{i}^{0}+2 \theta^{3} Y_{j}^{0}}{40 \theta^{2}-12 \theta^{4}+\theta^{6}-36}
\end{aligned}
$$

With Bertrand competition and inverse demand D2,

$$
\begin{gathered}
Q^{i}\left(Y_{i}, Y_{j} ; \theta\right)=\frac{\left(2-\theta^{2}\right) Y_{i}-\theta Y_{j}}{\left(4-\theta^{2}\right)(1-\theta)} ; \\
M^{i}\left(Y_{i}, Y_{j} ; \theta\right)=\frac{\left(2-\theta^{2}\right) Y_{i}-\theta Y_{j}}{4-\theta^{2}} . \\
y_{i}(\theta)=\frac{Y_{i}^{0}\left(-12+4 \theta+16 \theta^{2}-7 \theta^{4}+\theta^{5}+\theta^{6}-4 \theta^{3}\right)+Y_{j}^{0}\left(8 \theta-6 \theta^{3}+\theta^{5}\right)}{60 \theta+12 \theta^{2}-44 \theta^{3}+3 \theta^{4}+11 \theta^{5}-\theta^{6}-\theta^{7}-36}
\end{gathered}
$$

\footnotetext{
${ }^{47}$ Again, I assume the asymmetries are sufficiently small that the respective quantities are non-negative.

${ }^{48} \mathrm{~A}$ more detailed description of the calculation, including the arguments for $\lambda>0$, is available as supplementary material.
} 
With Cournot competition and inverse demand D2,

$$
\begin{gathered}
Q^{i}\left(Y_{i}, Y_{j} ; \theta\right)=\frac{(1+\theta)\left(2 Y_{i}-\theta Y_{j}\right)}{\left(4-\theta^{2}\right)} ; \\
M^{i}\left(Y_{i}, Y_{j} ; \theta\right)=\frac{2 Y_{i}-\theta Y_{j}}{4-\theta^{2}} . \\
y_{i}(\theta)=-\frac{Y_{i}^{0}\left(12+8 \theta-8 \theta^{2}-4 \theta^{3}\right)+Y_{j}^{0}\left(2 \theta^{4}-8 \theta-8 \theta^{2}+2 \theta^{3}\right)}{24 \theta+36 \theta^{2}-8 \theta^{3}-12 \theta^{4}+\theta^{6}-36}
\end{gathered}
$$

For the Hotelling case, defining $\theta=1-t$,

$$
\begin{gathered}
Q^{i}\left(Y_{i}, Y_{j} ; \theta\right)=\left(Y_{j}-Y_{i}+3(\theta-1)\right) / 6(\theta-1) ; \\
M^{i}\left(Y_{i}, Y_{j} ; \theta\right)=\left(Y_{i}-Y_{j}-3(\theta-1)\right) / 3 . \\
y_{i}(\theta)=\frac{9(\theta-1)-3 Y_{i}^{0}+3 Y_{j}^{0}+1}{54(\theta-1)+6}
\end{gathered}
$$

\subsection{Appendix 3: Cournot vs. Bertrand}

The framework can be adapted to the comparison of investments for Cournot $(\theta=\underline{\theta})$ and Bertrand $(\theta=\bar{\theta})$ competition with demand function D1 and D2. ${ }^{49}$ To avoid misunderstandings, I replace the substitution parameter with b. For D1, Figure 7 shows that investments are higher for soft (Cournot) competition, though the difference trivially approaches zero as $b$ does, because then both cases correspond to monopolies. As for the previous examples, an increase in $\theta$ is compatible with (C1)-(C4). Negative margin and cost-passthrough effects dominate the positive output and output-sensitivity effects.

Also, even though the figures do not address this case, it can be shown that, for asymmetric firms, the general patterns that hold for increasing substitutability reoccur: Competition (moving from Cournot to Bertrand competition) has a negative effect on the investments of firms that lag far behind the rival, but a positive effect on those that are substantially ahead of the rival. Also, marginal increases in the spillover parameter (starting from $\lambda=0$ ) have a negative effect on the differences between investments under Bertrand

\footnotetext{
${ }^{49}$ Even though $\theta$ does not affect demand functions $q^{i}\left(p^{i}, p^{j}\right)$, it affects equilibrium outputs, margins and profits. Therefore the terms $Q^{i}\left(Y_{i}, Y_{j} ; \theta\right), M^{i}\left(Y_{i}, Y_{j} ; \theta\right), \Pi^{i}\left(Y_{i}, Y_{j} ; \theta\right)$ still make sense.
} 


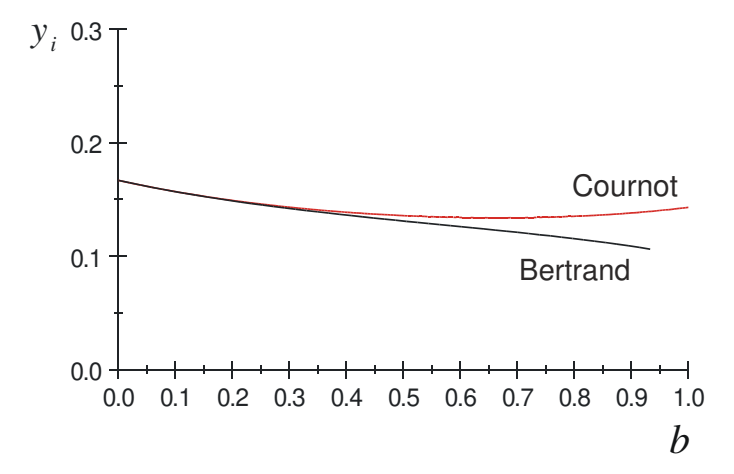

Figure 7: Cournot vs. Bertrand competition

and Cournot competition, respectively.

\section{References}

Aghion P, Harris C, Vickers J. Competition and growth with step-by-step innovation: An example. European Economic Review 1997;41; 771-782.

Aghion P, Harris C, Howitt P, Vickers J. Competition, imitation and growth with step-by-step innovation. Review of Economic Studies 2001;68; 467492 .

Bagwell K, Staiger RW. The sensitivity of strategic and corrective R\&D policy in oligopolistic industries. Journal of International Economics 1994;36; 133-150.

Bester H, Petrakis, E. The Incentives for Cost Reduction in a Differentiated Industry. International Journal of Industrial Organization 1993;11; 519534 .

Boone J. Competitive Pressure: The Effects on Investments in Product and Process Innovation. RAND Journal of Economics 2000;31; 549-569.

Chen Y, Schwartz M. Product Innovation Incentives: Monopoly vs. Competition. Journal of Economics and Management Strategy 2013;22; 513-528. 
Delbono F, Denicolò V. R\&D Investment in a Symmetric and Homogeneous Oligopoly: Bertrand vs. Cournot. International Journal of Industrial Organization 1990;8; 297-313.

Denicolò V, Zanchettin P., Competition, Market Selection and Growth. Economic Journal 2009;120, 761-785.

Gilbert R 2006. Looking for Mr. Schumpeter: Where are we in the Competition-Innovation Debate? In: Lerner J, Stern S (Eds), Innovation Policy and the Economy. MIT Press: Cambridge; 2006.p. 159-215.

Greenstein S, Ramey G. Market Structure, Innovation and Vertical Product Differentiation International Journal of Industrial Organization 1998;16; 285-311.

Hart O. The Market as an Incentive Mechanism. Bell Journal of Economics $1983 ; 14 ; 366-82$.

Hermalin B. The Effects of Competition on Executive Behavior. RAND Journal of Economics 1992; 23; 350-365.

Lee T, Wilde LL. Market Structure and Innovation: A Reformulation. Quarterly Journal of Economics 1980;94; 429-436.

Leahy D, Neary JP. Public Policy Towards R\&D in Oligopolistic Industries. American Economic Review 1997;87; 642-662.

Loury GC. Market Structure and Innovation. Quarterly Journal of Economics 1979;93; 395-410.

Milgrom P, Roberts J. Rationalizability, learning, and equilibrium in games with strategic complementarities. Econometrica 1990;58, 1255-1277.

Motta M. Competition Policy: Theory and Practice. Cambridge University Press: Cambridge; 2004.

Qiu LD. On the Dynamic Efficiency of Bertrand and Cournot Equilibria. Journal of Economic Theory 1997;75: 213-229. 
Raith M. Competition, Risk, and Managerial Incentives. American Economic Review 2003;93; 1425-1436.

Sacco D, Schmutzler A. Is there a U-shaped relation between competition and investment? International Journal of Industrial Organisation $2011 ; 29 ; 65-73$.

Schmidt, KM. Managerial Incentives and Product Market Competition. Review of Economic Studies 1996;64; 191-213.

Schmutzler A. Is competition good for innovation? A simple approach to an unresolved question. Foundations and Trends in Microeconomic Analysis 2010; 5; 355-428.

Segal I, Whinston M. Antitrust in Innovative Industries, American Economic Review 2007;97; 1703-1730

Shapiro C 1989. Theories of Oligopoly Behavior. In: Schmalensee R, Robert DW (Eds), Handbook of Industrial Organization. North Holland: Amsterdam; 1989. p.327-414.

Syverson C. Market Structure and Productivity: A Concrete Example. Journal of Political Economy 2004;112; 1181-1222.

Vives X. Innovation and Competitive Pressure. Journal of Industrial Economics 2008;56; 419-469.

Weinschenk P, 2010. Entry and Incumbent Innovation. Working Paper. Max Planck Institute for Research on Collective Goods, Bonn. 